\title{
Soy Protein-Gum Karaya Conjugate: Emulsifying Activity and Rheological Behavior in Aqueous System and Oil in Water Emulsion
}

\author{
Elhamalsadat Shekarforoush ${ }^{1} \cdot$ Hamed Mirhosseini $^{1} \cdot$ Md Zaidul Islam Sarker $^{3}$ • \\ Sanja Kostadinović ${ }^{4} \cdot$ Hasanah Mohd Ghazali ${ }^{2} \cdot$ Kharidah Muhamad $^{2}$. \\ Shadi Samaram ${ }^{1}$
}

Received: 26 March 2015 / Revised: 2 November 2015 / Accepted: 4 November 2015

(C) AOCS 2015

\begin{abstract}
The main objective of this study is to investigate the effects of mixing and conjugation of soy protein isolate (SPI) with gum karaya on the characteristics of the hybrid polymer (protein-gum) in both aqueous systems and oil-in-water $(\mathrm{O} / \mathrm{W})$ emulsions. It was hypothesized that the covalent linkage of gum karaya with SPI would improve the emulsifying activity and rheological properties of both polymers. Conjugation occurred under controlled conditions (i.e., $60{ }^{\circ} \mathrm{C}$ and $75 \%$ relative humidity, 3 days). The conjugated hybrid polymer produced smaller droplet with better uniformity, higher viscosity and stronger emulsifying activity than native gum karaya, suggesting the conjugated polymer provided a bulkier secondary layer with more efficient coverage around oil droplets, thereby inducing stronger resistance against droplet aggregation and flocculation. Emulsions containing the native gum karaya produced the largest droplet size among all prepared emulsions $\left(D_{3,2}=8.6 \mu \mathrm{m} ; D_{4,3}=22.4 \mu \mathrm{m}\right)$; while the emulsion containing protein-gum conjugate $(1: 1 \mathrm{~g} / \mathrm{g})$ had the smallest droplet size $\left(D_{3,2}=0.2 \mu \mathrm{m} ; D_{4,3}=0.7 \mu \mathrm{m}\right)$ with lower polydispersity. The protein-gum conjugate $(1: 1 \mathrm{~g} / \mathrm{g})$ also showed the highest elastic and viscous modulus, the lowest
\end{abstract}

Hamed Mirhosseini

hamedmi@upm.edu.my

1 Department of Food Technology, Faculty of Food Science and Technology, Universiti Putra Malaysia, 43400 UPM Serdang, Selangor, Malaysia

2 Department of Food Science, Faculty of Food Science and Technology, Universiti Putra Malaysia, 43400 UPM Serdang, Selangor, Malaysia

3 Faculty of Pharmacy, International Islamic University, Kuantan Campus, 25200 Kuantan, Pahang D/M, Malaysia

4 Faculty of Agriculture, University "Goce Delčev", Krste Misirkov bb, 2000 Štip, Macedonia polydispersity (span) and the highest emulsifying activity among all native, mixed and conjugated polymers. Therefore, the percentage of gum karaya used for production of $\mathrm{O} / \mathrm{W}$ emulsion can be decreased by partially replacing it with the conjugated gum.

Keywords Gum karaya $\cdot$ Soy protein isolate . Conjugation process $\cdot$ Maillard reaction $\cdot$ SDS-PAGE electropherogram $\cdot$ Scanning electron microscopy $($ SEM)

\section{Introduction}

In recent years, the production of new food ingredients with more desirable functional properties has been receiving much attention. There are many physical, chemical and/or enzymatic reactions applied for producing new food ingredients. The conjugation process between a protein and polysaccharide gum through the Maillard reaction is one of most important reactions, which can result in the formation of a new ingredient with more desirable functions [1-3]. The natural reaction, which occurs spontaneously by applying heat, begins with a condensation reaction between amino acids (protein) and a carbonyl-containing moiety (polysaccharide). A Schiff base is initially produced during the Maillard reaction. Subsequently, a more stable ketosamine is formed by an Amadori rearrangement [4]. A wide variety of compounds including brown pigments (called melanoidins) appears in the final stages of the Maillard reaction [5]. This reaction occurs between a carbonyl group from a reducing sugar and amino group from a protein. Maillard reaction can significantly affect the thermal stability, physiochemical and functional properties of both polymers (i.e. polysaccharide and protein). This may be because of the substantial changes in chemical composition and/or molecular structures of the 
applied polymers during Maillard reaction [6, 7]. For conjugation purposes, it is necessary to apply a proper protein for conjugation, which is compatible with the target polysaccharide. Otherwise the conjugation process can induce a negative effect on the emulsifying activity and other functional properties of both applied polymers [8]. The degree and rate of the Maillard reaction depend on several factors such as type and proportion of protein and polysaccharide, reaction time and temperature [9].

Several studies $[10,11]$ have been carried out to investigate the effect of chemical modification on the functional properties of gum karaya (GK). However, there are no studies that report on the influence of the Maillard reaction between gum karaya (GK) and soy protein isolate (SPI) in aqueous systems and oil-in-water $(\mathrm{O} / \mathrm{W})$ emulsions containing gum karaya. This study investigated the effect of mixing and conjugation process of gum karaya with SPI on the functional properties of the hybrid polymer in aqueous systems and oil-in-water (O/W) emulsions. Eight formulations were tested: SPI, GK, a and soy protein/GK physical mixtures and conjugates at 1:1, 1:2, and 1:3 w/w. The emulsifying characteristics of the SPI-GK conjugates were assessed by viscosity, dynamic rheology, average droplet size and size distribution, and morphology. The interaction effects of GK and SPI have not been investigated previously.

\section{Experimental Section}

\section{Chemical and Materials}

GK from Sterculia urens was obtained from Nutriroma Co. (Hyderabad, Andhra Pradesh, India). SPI was purchased from Protein Technologies International (St. Louis, MO, USA). Canola oil was bought from a local supermarket (Selangor, Malaysia). Citric acid was supplied by Riedel-de Haën (Victoria, Australia). In this study, $\mathrm{NaCl}$, acrylamide gels, methanol, acetic acid and Coomassie Brilliant Blue (R-250) were purchased from Merck KGaA (Darmstadt, Germany). $\mathrm{NaOH}, \mathrm{HCl}$, Tris-HCl buffer (pH 6.8), mercaptoethanol, bromophenol blue and sodium benzoate were supplied by Fisher Scientific (Pittsburgh, PA, USA).

\section{Conjugation of Soy Protein Isolate to Gum Karaya}

The conjugation of SPI to GK was carried out according to a method described by Kasran et al. [12]. Solutions of PSIGK mixtures at ratios of 1:1, 1:2 and 1:3 g/g were prepared by mixing $1 \% \mathrm{w} / \mathrm{v}$ aqueous solutions of PSI and GK in their proper proportions. The latter aqueous solution's $\mathrm{pH}$ was adjusted to 7.0 by adding $0.1 \mathrm{M} \mathrm{NaOH}$; the GK solution was stored overnight at room temperature $\left(25 \pm 1{ }^{\circ} \mathrm{C}\right)$ to facilitate hydration. The PSI-GK solutions were lyophilized using a freeze dryer (Free Zone 18, Model 77550, Labconco Corp., Kansas City, MO, USA). The freeze drying was carried out at $-40{ }^{\circ} \mathrm{C}$ for 2 days. Then, the lyophilized samples were milled and the powders were maintained at $4{ }^{\circ} \mathrm{C}$ for overnight $(\sim 12 \mathrm{~h})$. The PSI-GK powders were incubated at $60{ }^{\circ} \mathrm{C}$ and $75 \%$ relative humidity (RH) for 3 days. The conjugates were then frozen overnight at $-20{ }^{\circ} \mathrm{C}$, freeze dried, and stored at $4{ }^{\circ} \mathrm{C}$.

\section{Preparation of O/W Emulsion}

Oil-in-water $(\mathrm{O} / \mathrm{W})$ emulsions were prepared according to a previously described method [2]. Emulsifier (SPI, GK, or SPI-GK mixtures or conjugates) was added to the aqueous continuous phase, which contained $0.1 \mathrm{w} / \mathrm{w}$ sodium benzoate and $0.3 \mathrm{w} / \mathrm{w}$ citric acid, stirred at room temperature $\left(25 \pm 1{ }^{\circ} \mathrm{C}\right)$ and kept overnight at $25^{\circ} \mathrm{C}$ to fully hydrate the continuous phase. Then, canola oil (20\% w/w) was gradually added to the continuous phase and stirred for $5 \mathrm{~min}$ to produce the coarse emulsion. Finally, all coarse emulsions were homogenized by a high-pressure homogenizer (APV, Crawley, UK) at $30 \mathrm{MPa}$ for three cycles [2].

\section{Analytical Tests}

\section{Sodium Dodecyl Sulfate-Polyacrylamide Gel} Electrophoresis (SDS-PAGE)

The formation of SPI-GK covalent bonds was detected by SDS-PAGE electrophoresis as described by Laemmli [13]. A capillary electrophoresis system (Agilent Technologies, CA, USA) equipped with a diode array detector and a temperature control device $\left(25 \pm 1{ }^{\circ} \mathrm{C}\right)$, was applied. First, acrylamide separating and stacking gels containing $0.1 \% \mathrm{w} / \mathrm{v}$ SDS were prepared at different concentrations of 12 and $4 \%$, w/v respectively. The solutions containing GK and SPI-GK conjugates $(0.5 \% \mathrm{w} / \mathrm{v})$ were prepared in $0.0625 \mathrm{M}$ Tris-HCl buffer (pH 6.8) with SDS (2\% $\mathrm{w} / \mathrm{w})$, mercaptoethanol ( $5 \% \mathrm{w} / \mathrm{w})$, and bromophenol blue $(0.012 \% \mathrm{w} / \mathrm{w})$. The mixtures were loaded into the gel after heating at $95{ }^{\circ} \mathrm{C}$ for $4 \mathrm{~min}$. Electrophoresis was carried out at $100 \mathrm{~V}$ for $90 \mathrm{~min}$, with a Tris-glycine elution buffer (pH 8.3) containing $0.125 \% \mathrm{w} / \mathrm{w}$ SDS. After electrophoresis was completed, the gels were removed and stained with Coomassie Brilliant Blue R-250, and then treated with methanol-acetic acid-water (50:10:40, v/v/v). Electrophoresis runs were carried out in duplicate for each sample.

\section{Scanning Electron Microscopy (SEM)}

Powder granules $(\sim 0.5 \mathrm{~g})$ were directly attached to an aluminum specimen by using double-sided carbon adhesive 
tape. A Scancoat Six sputter coater (BOC Edwards, Wilmington, MA, USA) was used to cover the powder granules with a thin gold coating. This gold coating is applied to induce sufficient conductivity for SEM imaging. Digital topographical images were captured by a scanning electron microscope (Quanta 200 ${ }^{\mathrm{TM}}$ FEG, FEI Co., Hillsboro, OR, USA). The high-vacuum secondary-electron imaging mode was applied at 500 $\times$ magnification [14]. SEM imaging was performed in triplicate for each sample.

\section{Determination of Droplet Size and Distribution}

In this study, the average droplet size and size distribution of final emulsions and their continuous phase containing gum solution were individually measured. This helps us to monitor the changes in the droplet size distribution after adding canola oil to the continuous phase during emulsion preparation. If the gum solution or continuous phase does not provide the proper function, the final emulsion has significantly larger droplets and higher polydispersity than its continuous phase. The droplet size and size distribution of $\mathrm{O} / \mathrm{W}$ emulsions were measured by a means of a Mastersizer 2000S particle size analyzer (Malvern Instruments Inc., Westborough, MA, USA). For measurement of droplet size of $\mathrm{O} / \mathrm{W}$ emulsion, the refractive indices of 1.466 and 1.334 were separately adjusted for the emulsion dispersed phase (containing canola oil) and continuous phase (containing gum solution), respectively [15]. As recommended by Malvern Instruments Inc., It is necessary to adjust such refractive indices in the instrument settings prior to analysis. Otherwise, the accuracy of data will not be guaranteed. The surface-weighted mean $\left(D_{3,2}\right)$ and volume-weighted mean diameter $\left(D_{4,3}\right)$ were measured to determine the average droplet size of the $\mathrm{O} / \mathrm{W}$ emulsion. $D_{3,2}$ is used to estimate the specific surface area of freshly-made emulsions; while $D_{4,3}$ is used to investigate the effect of storage on the droplet-size distribution [12].

For measuring droplet size of the continuous phase, the gum solution $(0.5 \% \mathrm{w} / \mathrm{w})$ was prepared and stirred by a magnetic stirrer for $1 \mathrm{~h}$ at $25^{\circ} \mathrm{C}$. The gum solution is left to hydrate for $24 \mathrm{~h}$ before analysis. The same Malvern instrument was used to determine the span (or droplet size distribution) of the continuous phase containing the gum solution. Span and average droplet size $\left(D_{4,3}\right)$ were estimated via the following equations:

Span $=D[v, 0.9]-D[v, 0.1] / D[v, 0.5]$

$D[4,3]=\Sigma n_{i} d_{i}^{4} / \Sigma n_{i} d_{i}^{3}$

where $D(v, 0.1), D(v, 0.5)$, and $D(v, 0.9)$ are the average diameters at 10,50 and $90 \%$ cumulative volume, respectively; and $n_{i}$ is the number of droplets with diameter $d_{i}$ [15].

\section{Measurement of Dynamic Rheological Properties}

In this study, the apparent viscosity, elastic $\left(G^{\prime}\right)$ and viscous moduli $\left(G^{\prime \prime}\right)$ of GK dissolved in the continuous phase of $\mathrm{O} / \mathrm{W}$ emulsions were measured to quantify the elastic energy stored or lost through flow [16, 17]. Dynamic oscillatory testing was performed by means of a RheoStress 600 rheometer (Haake Instruments, Karlsruhe, Germany) with the sensor $\mathrm{C} 60 / 2^{\circ}$. A $1-\mathrm{mL}$ sample of continuous phase (without oil) was placed on the rheometer plate and allowed to equilibrate for $10 \mathrm{~min}$ at $25^{\circ} \mathrm{C}$. Different shear rates ranging from 10 to $2001 / \mathrm{s}$ were applied to the samples to assess the viscosity. The viscoelastic properties were measured by frequency oscillation to determine the $G^{\prime}$ and $G^{\prime \prime}$ moduli. The applied stress in the frequency sweep test $(0.01-10 \mathrm{~Hz})$ was $0.5 \mathrm{~Pa}$. The dynamic viscoelastic modulus $\left(G^{*}\right)$ is dependent on the $G^{\prime}$ and $G^{\prime \prime}$ moduli and is a function of the oscillation frequency $[16,17]$ :

Stress $(\sigma)=\sigma_{0} \sin (t \omega+\delta)$

$\operatorname{Strain}(\gamma)=\gamma_{0} \sin (t \omega)$

Elastic (or storage) odule $G^{\prime}=\left(\sigma_{0} / \gamma_{0}\right) \cos \delta$

Viscous (or loss) module $G^{\prime \prime}=\left(\sigma_{0} / \gamma_{0}\right) \sin \delta$

$G^{*}(\omega)=\left(\sigma / \gamma_{0}\right) e^{i \delta(\omega)}=G^{\prime}(\omega)+i G^{\prime \prime}(\omega)$

where $(\sigma),(\gamma)$, and phase shift $(\delta)$, relate to the three rheological stress-strain oscillation variables, and $\sigma_{0}$ and $\gamma_{0}$ are the amplitudes of stress and strain $(t=0)$.

\section{Determination of Emulsion Stability}

A test tube containing $13 \mathrm{~mL}$ fresh emulsion was maintained at $25 \pm 1{ }^{\circ} \mathrm{C}$ for 30 days [18]. The cream layer at the top surface was then separated from the translucent/turbid serum. Then the emulsion stability (ES) was determined based on the following equation:

$\mathrm{ES}(\%)=[\mathrm{HE}-(\mathrm{HS}+\mathrm{HC}) / \mathrm{HE}] \times 100$

where $\mathrm{HE}$ is the overall height of the emulsion, and $\mathrm{HC}$ and HS are the heights of the cream and serum layers, respectively [19]. The test was carried out in triplicate for each sample.

\section{Experimental Design and Data Analysis}

The effects of mixing and conjugation of PSI and GK on functional characteristics of GK were examined by creating a full factorial design. The GK solutions served as a control. The differences between samples were assessed via emulsion stability, rheological properties, average droplet 
Table 1 Significant $(p<0.05)$ or insignificant $(p>0.05)$ effect of conjugation variables on the characteristics of gum karaya-soy protein isolate hybrid polymer in an aqueous system and oil in water emulsion

\begin{tabular}{|c|c|c|c|c|c|c|}
\hline \multirow[t]{2}{*}{ System } & \multirow[t]{2}{*}{ Response } & \multirow[t]{2}{*}{$R^{2}$} & \multirow[t]{2}{*}{ Significance } & \multicolumn{2}{|c|}{ Main effects } & \multirow{2}{*}{$\begin{array}{l}\text { Interaction effects } \\
x_{1} x_{2}\end{array}$} \\
\hline & & & & $x_{1}$ & $x_{2}$ & \\
\hline \multirow[t]{6}{*}{ Oil/water emulsion } & \multirow[t]{2}{*}{ Volume weighted mean $(\mu \mathrm{m})$} & \multirow[t]{2}{*}{0.99} & $p$ value & $<0.0001$ & $<0.0001$ & $<0.0001$ \\
\hline & & & $F$ ratio & 7397 & 784 & 247 \\
\hline & \multirow[t]{2}{*}{ Surface weighted mean $(\mu \mathrm{m})$} & \multirow[t]{2}{*}{0.99} & $p$ value & $<0.0001$ & $<0.0001$ & 0.0014 \\
\hline & & & $F$ ratio & 3831 & 132 & 24 \\
\hline & \multirow[t]{2}{*}{ Viscous modulus $\left(G^{\prime \prime}, \mathrm{Pa}\right)$} & \multirow[t]{2}{*}{0.97} & $p$ value & 0.0002 & 0.0002 & 0.0001 \\
\hline & & & $F$ ratio & 70.42 & 49 & 56 \\
\hline \multirow[t]{10}{*}{ Aqueous system } & \multirow[t]{2}{*}{ Span } & \multirow[t]{2}{*}{0.99} & $p$ value & $<0.0001$ & $<0.0001$ & $<0.0001$ \\
\hline & & & $F$ ratio & 32,592 & 276 & 90 \\
\hline & \multirow[t]{2}{*}{ Uniformity } & \multirow[t]{2}{*}{0.99} & $p$ value & $<0.0001$ & $<0.0001$ & $<0.0001$ \\
\hline & & & $F$ ratio & 31,247 & 2754 & 3676 \\
\hline & \multirow[t]{2}{*}{ Viscous modulus $\left(G^{\prime \prime}, \mathrm{Pa}\right)$} & \multirow[t]{2}{*}{0.98} & $p$ value & $<0.0001$ & $<0.0001$ & 0.0008 \\
\hline & & & $F$ ratio & 138 & 78.45 & 29 \\
\hline & \multirow[t]{2}{*}{ Elastic modulus $\left(G^{\prime}, \mathrm{Pa}\right)$} & \multirow[t]{2}{*}{0.99} & $p$ value & $<0.0001$ & $<0.0001$ & 0.0003 \\
\hline & & & $F$ ratio & 2624 & 495 & 41 \\
\hline & \multirow[t]{2}{*}{ Viscosity (mPa s) } & \multirow[t]{2}{*}{0.98} & $p$ value & 0.0004 & $<0.0001$ & 0.0002 \\
\hline & & & $F$ ratio & 52 & 121 & 45 \\
\hline
\end{tabular}

$x_{1}$ and $x_{2}$ represents the single effect of temperature and protein to gum ratio, respectively. $x_{1} x_{2}$ represents the interaction between temperature and protein to gum ratio

Fig. 1 SDS-PAGE of soy protein isolates (SPI) and gum karaya $(\mathrm{GK})$ at different ratio (1:3, 1:2 and 1:1) before and after dry-heating at $60{ }^{\circ} \mathrm{C}$ and $75 \%$ humidity

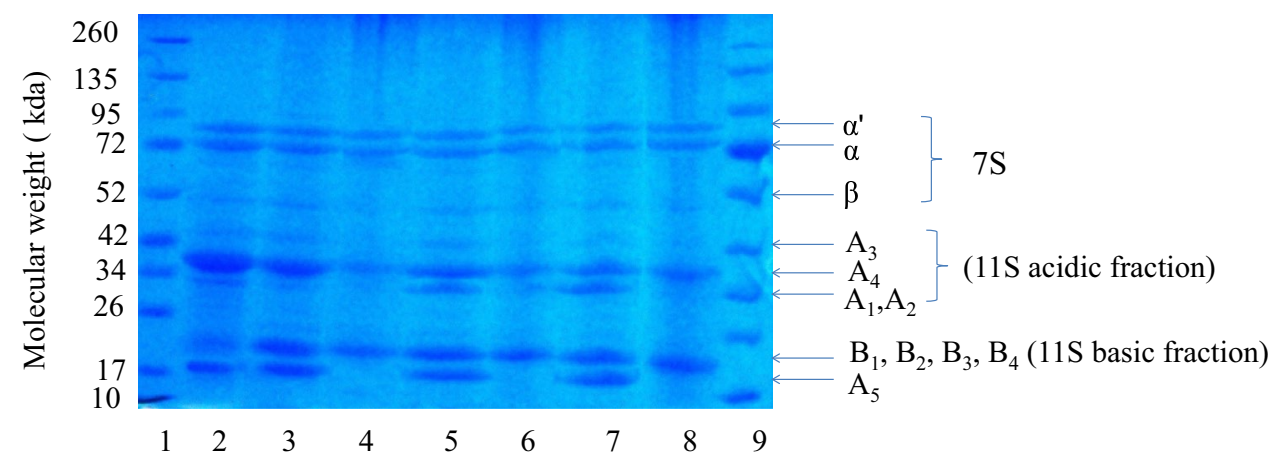

size and size distribution, and morphological structure of all samples. Minitab ${ }^{\circledR}$ version 16 (Minitab Inc., State College, PA, USA) software was used to generate the experimental design and facilitate data analysis [15]. One-way and two-way analysis of variance (ANOVA) were used to determine the significant difference within and between treatments (Table 1).

\section{Results and Discussion}

\section{SDS-PAGE Electrophoresis}

The covalent coupling of PSI and GK induced by the Maillard reaction was detected by SDS-PAGE [2, 20, 21]. Figure 1 depicts electrophoresis results for aqueous solutions of marker proteins (lane 1), SPI (lane 2), GK (lane 9), their mixtures (lanes 3, 5 and 7) and conjugates (lanes 4, 6 and 8). SPI produced two fractions: $\beta$-conglycinin (7S) and glycinin (11S) [22]. $\beta$-conglycinin is composed of $\alpha^{\prime}$, $\alpha$ and $\beta$ subunits [22, 23]; while glycinin has both acidic and basic subunits [24]. SDS-PAGE analysis of GK showed no clear identifiable bands. SDS-PAGE data for SPI-GK mixtures have equivalent patterns to those for SPI alone, perhaps indicating that SPI-GK mixtures did not produce electrostatic complexes of the two. On the other hand, a large band of immobile substance was observed for the SDS-PAGE data for the dry heated conjugated samples. The dry-heat treatment induced the very predominant polydisperse bands, indicating that a hybrid polymer with high molecular weight was formed after inducing the Maillardtype reaction. 

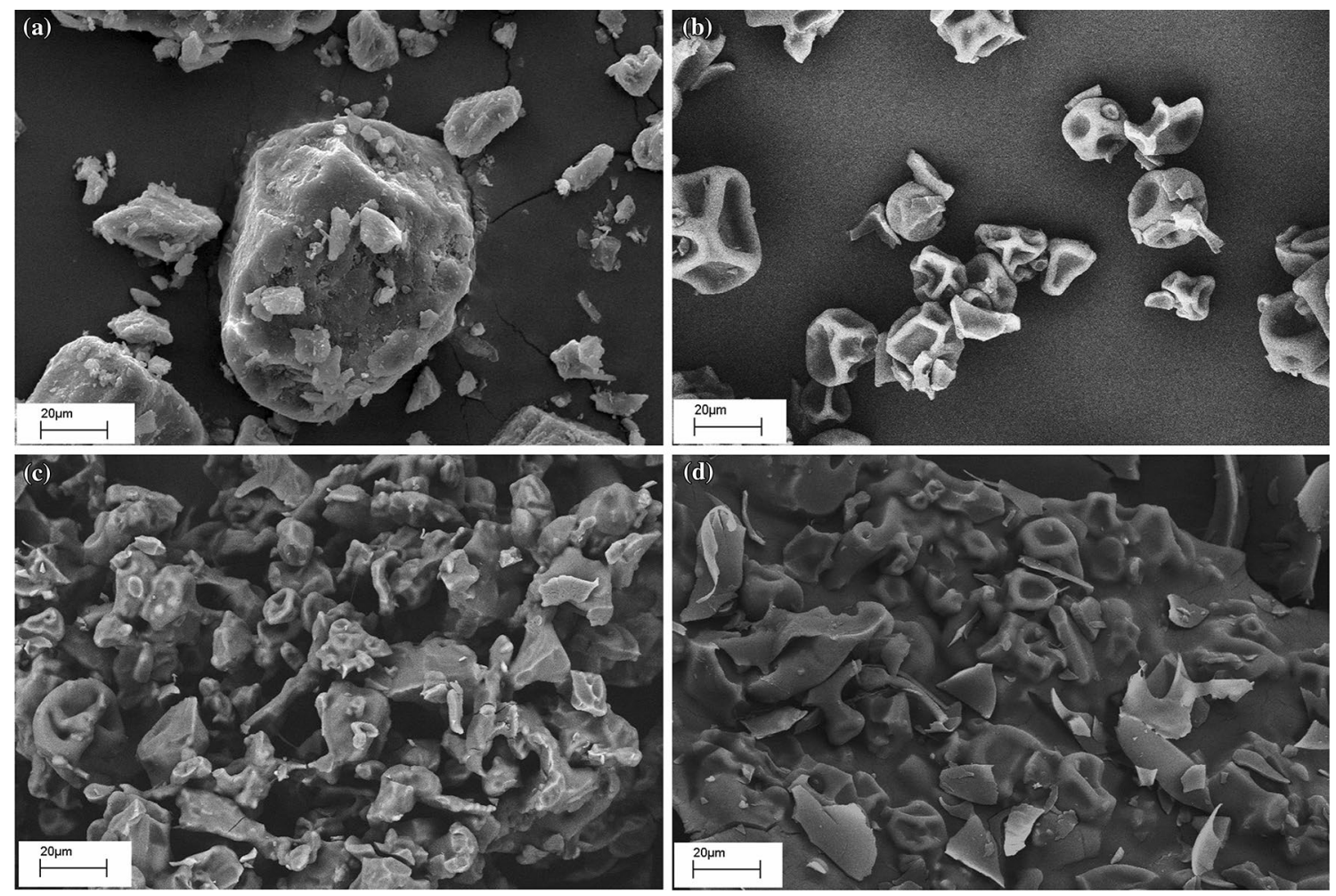

Fig. 2 Scanning electron micrographs of gum karaya (GK) (a), soy protein isolate (SPI) (b), the protein-gum mixture (1:1) (c) and the conjugated hybrid polymer (1:1) (d) (magnification $\times 500$; scale bar $20 \mu \mathrm{m})$

As shown in Fig. 1, SPI-GK conjugates exhibited thicker and darker boundary layers than GK and SPI-GK mixtures, confirming that the Maillard reaction had occurred. In most cases, conjugation under dry heating condition produced a biopolymer with a higher molecular weight than the original polymer (Fig. 1), consistent with previous reports for conjugation of SPI and other polysaccharide gums [25-27].

\section{Morphological Surface Structure}

The morphological structures of SPI, GK, and their physical mixtures and conjugates $(1: 1 \mathrm{w} / \mathrm{w})$ are shown in Fig. 2a-d. The changes induced by dry-heat conditions are visible by comparing the images for GK and SPI-GK conjugates. Multifaceted and slippery surfaces were observed for GK granules (Fig. 2a), consistent with a previous report [28]. Images for SPI granules reflected polyhedral surface morphology (Fig. 2b). The SEM micrograph for the PSIGK mixture shows no identifiable bonding (Fig. 2c). In contrast, some changes in the particle structure and shape occurred as a result of conjugation (Fig. 2d). The electromicrogram displays a very compact random microstructure for the globular SPI and GK components, perhaps indicating the formation of covalent linkages between SPI and GK.
Table 2 Volume weighted mean diameter $\left(D_{4,3}\right)$ and surface weighted mean $\left(D_{3,2}\right)$ of $\mathrm{O} / \mathrm{W}$ emulsions by gum karaya $(\mathrm{GK})$ or its mixtures and conjugates with soy protein isolate (SPI)

\begin{tabular}{llrl}
\hline Sample & SPI:GK ratio & \multicolumn{1}{l}{$D_{4,3}(\mu \mathrm{m})$} & \multicolumn{1}{l}{$D_{3,2}(\mu \mathrm{m})$} \\
\hline Gum karaya & $0: 1$ & $22.40 \pm 0.19^{\mathrm{a}}$ & $8.657 \pm 0.04^{\mathrm{a}}$ \\
SPI-GK mixture & $1: 1$ & $2.78 \pm 0.01^{\mathrm{c}}$ & $0.888 \pm 0.07^{\mathrm{c}}$ \\
& $1: 2$ & $2.91 \pm 0.07^{\mathrm{c}}$ & $1.135 \pm 0.03^{\mathrm{b}}$ \\
& $1: 3$ & $3.25 \pm 0.07^{\mathrm{b}}$ & $1.181 \pm 0.06^{\mathrm{b}}$ \\
SPI-GK conjugate & $1: 1$ & $0.73 \pm 0.07^{\mathrm{e}}$ & $0.278 \pm 0.08^{\mathrm{d}}$ \\
& $1: 2$ & $1.78 \pm 0.01^{\mathrm{d}}$ & $0.331 \pm 0.02^{\mathrm{d}}$ \\
& $1: 3$ & $1.92 \pm 0.07^{\mathrm{d}}$ & $0.440 \pm 0.01^{\mathrm{d}}$ \\
\hline
\end{tabular}

SPI soy protein isolate, $G K$ gum karaya

${ }^{a-e}$ Significant different at the confident level of $95 \%$

Functional Properties of Gum Karaya (GK) and Soy Protein Isolate-GK Conjugates in Aqueous Systems and $\mathrm{O} / \mathrm{W}$ Emulsions

Effect of Conjugation Process on Average Droplet Size Table 2 shows the changes in the volume weighted mean (or average droplet size) of emulsions formed by GK, PSI-GK mixtures, and PSI-GK conjugates. The PSIGK conjugates $(1: 1 \mathrm{~g} / \mathrm{g})$ had the smallest droplet size (i.e., 
$D_{3,2}=0.2 \mu \mathrm{m}$ and $\left.D_{4,3}=0.7 \mu \mathrm{m}\right)$ and a uniform size distribution, while emulsions formed by GK possessed the largest size (i.e., $D_{3,2}=8.6 \mu \mathrm{m}$ and $D_{4,3}=22.4 \mu \mathrm{m}$ ). The difference in droplet size may reflect differences in the hydrophilic/lipophilic balance (HLB) of the two emulsifiers [29]. There is more sensitivity to aggregation and flocculation in $\mathrm{O} / \mathrm{W}$ emulsions with a wide droplet size range. Maintaining a smaller droplet size enables the emulsion to remain stable for a longer time. Previous researchers [20] also showed that whey protein-maltodextrin conjugates had better emulsifying stability than the native polymer before conjugation. Kato [30] stated that the hydrophobic/hydrophilic structure of the conjugated biopolymer was responsible for making smaller droplets in emulsions than the non-conjugated polymer.

The span ranged from 0.4 to 1.9 , depending on the PSI:GK ratio. The Maillard reaction led to a significant decrease in the span, indicating a more monodisperse population of dispersions. The PSI-GK conjugate $(1: 1 \mathrm{t} w / \mathrm{w})$ possessed the narrowest droplet size distribution among all tested emulsions. It was reported that native fenugreek gum, as opposed to protein-free fenugreek gum, produced a very stable $\mathrm{O} / \mathrm{W}$ emulsion with smaller droplet size. The researchers explained that the formation of smaller emulsion droplets induced by native fenugreek gum containing protein might be due to its protein fraction [19].

\section{Effect of Conjugation with Soy Protein Isolate on Dynamic Rheological Properties of Gum Karaya}

The physical stability of an emulsion is significantly influenced by its viscosity and rheological properties [31, 32]. The results showed that all SPI-GK mixtures and conjugates had the high apparent viscosity. They showed the non-Newtonian pseudoplastic behavior in both aqueous system and emulsion (i.e., apparent viscosity decreased with increasing shear rate; Fig. 4). The control (GK) had a significantly lower apparent viscosity than the proteingum mixtures and conjugates in both aqueous system and emulsion. This trend is explained by the fact that most anionic proteins can form a complex coacervate with anionic polysaccharides; while the linkage of a cationic protein (like soy protein isolate) and an anionic polysaccharide gum (like gum karaya) can result in the formation of a conjugated hybrid polymer with larger molecular structure than protein or gum alone [20,39]. The conjugation usually has a supportive impact on emulsifying activity and other functional properties of a protein in its isoelectric point $[8,14,18]$. A native protein is very sensitive to the changes in $\mathrm{pH}$ changes and it may simply precipitate at its isoelectric point. However, it does not show such high $\mathrm{pH}$ sensitivity after conjugation with a polysaccharide gum via Maillard reaction (or conjugation). In fact, the conjugated protein is usually less sensitive than its native form. In fact, the linkage of a native protein with a polysaccharide gum can result in the formation of a hybrid polymer with larger molecular weight, which usually shows less sensitivity than its native form. This may be explained by the fact that the conjugated polymer does not behave like a native protein or a native gum [33].

Among all samples, the SPI-GK conjugate $(1: 1 \mathrm{w} / \mathrm{w})$ produced the highest viscosity in both aqueous system and $\mathrm{O} / \mathrm{W}$ emulsion (Fig. 4). This might be explained by the fact that the covalent linkage between the protein and gum resulted in the formation of a conjugated hybrid polymer with higher molecular weight, which provided higher viscosity than the native gum and SPI in both aqueous system and $\mathrm{O} / \mathrm{W}$ emulsion. In fact, such conjugated hybrid polymer is bigger than GK and SPI alone, thus providing more viscous aqueous system and emulsion. The results showed that the GK-SPI mixture did not provide such high viscosity as compared to the GK-SPI conjugate. Dynamic oscillatory testing was applied to determine the viscoelastic behavior. Typically solid-like behavior is apparent in a real gel; while liquid-like properties is apparent in a concentrated (viscous) solution [34, 35]. Figure 5 shows that the elastic modulus of SPI-GK mixtures and conjugates $\left(G^{\prime} \sim 15-35 \mathrm{~Pa}\right)$ was higher than their viscous modulus $\left(\mathrm{G}^{\prime \prime} \sim 1-16 \mathrm{~Pa}\right)$ in both aqueous system and emulsion.

During one oscillation at $0.1-10 \mathrm{~Hz}$, there is the sufficient time for bonds in a biopolymer to break and reform, resulting in gel-like behavior [36]. Previous researchers [37] showed that fenugreek gum and Prosopis flexuosa DC seed gum had stronger gel-like behavior than the viscouslike behavior at the same frequencies $\left(G^{\prime}>G^{\prime \prime}\right)$. The current research showed that the SPI-GK conjugate $(1: 1 \mathrm{w} / \mathrm{w})$ had a significantly highest elastic and viscous modulus $\left(G^{\prime}\right.$ and $G^{\prime \prime}$ ) among all conjugates in both emulsion and aqueous systems; while a SPI-GK mixture $(1: 3 \mathrm{w} / \mathrm{w})$ showed the weakest elastic behavior among all samples, perhaps reflecting a profound effect of conjugation on the chemical composition and molecular structure of GK, consistent with the results obtained by Mirhosseini et al. [17].

\section{Effect of Conjugation on Emulsification Activity of Gum Karaya}

The emulsifying activity of GK and SPI-GK mixtures and conjugates was compared through measurements of physical stability and droplet-size distribution. Table 2 shows droplet-size distributions $\left(D_{4,3}\right.$ and $\left.D_{3,2}\right)$ of the different emulsifiers. $D_{4,3}$ is the more sensitive than $D_{3,2}$ and it is used to monitor the presence of large droplets caused by aggregation and flocculation [38]. As shown in Table 2, the emulsifying activity of GK was improved by significant reduction of the droplet size from $22.40 \pm 0.19 \mu \mathrm{m}$ (for 
Fig. 3 Particle size distribution of the native gum karaya (control), its mixtures $(M)$ and conjugated forms $(C) ; a-e$ significant different at $p<0.05$

Fig. 4 Steady shear rate dependence and viscosity of the native, mixed- and conjugated gum karaya in an aqueous system (a) and an oil in water $(\mathrm{O} / \mathrm{W})$ emulsion $(\mathbf{b})$ at different ratios (1:1, 1:2 and 1:3), $C$ conjugated polymer, $M$ mixed polymer
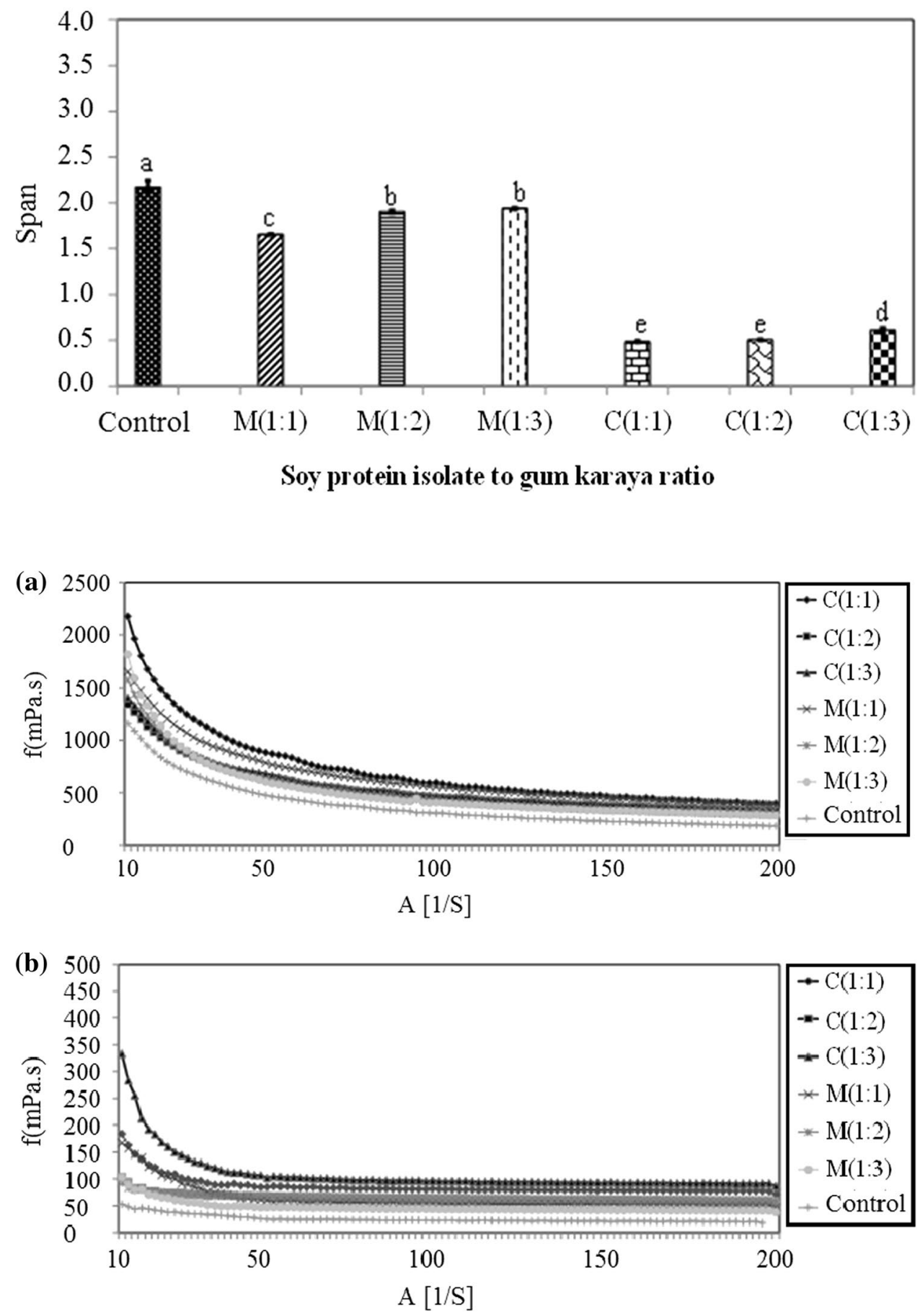

GK) to $2.78 \pm 0.01 \mu \mathrm{m}$ (for the SPI-GK mixture, $1: 1 \mathrm{w} / \mathrm{w}$ ) and $0.73 \pm 0.07 \mu \mathrm{m}$ (SPI-GK conjugate, $1: 1 \mathrm{w} / \mathrm{w})$. In fact, the emulsions stabilized by the latter emulsifier were more stable and were smaller in diameter, with lower polydispersity than the other emulsions (Table 2).

Figure 6 also depicts the emulsifying stability of all emulsions at $25{ }^{\circ} \mathrm{C}$. The results show that the emulsions by SPI or GK alone were less stable than SPI-GK mixtures or conjugates. In fact, the conjugates had better emulsifying activity than GK, perhaps indicating the significant positive effect of conjugation on the emulsifying activity of GK. A similar observation was also reported by previous researchers [39-41] for several different polysaccharide gums and proteins. The positive impact of conjugation on the emulsifying activity of GK may be attributable to several different factors. Yadav et al. [2] explained that the presence of protein in corn fiber gum more efficiently supported emulsion droplets against collision and flocculation. In this study, the 
Fig. 5 Viscous modulus $\left(G^{\prime \prime}\right)$ and elastic modulus $\left(G^{\prime}\right)$ of gum karaya in aqueous system (a) and oil in water $(\mathrm{O} / \mathrm{W})$ emulsion (b); $C$ conjugated polymer, $M$ mixed polymer; $A-F$ significant $(p<0.05)$ difference in term of elastic modulus $\left(G^{\prime}\right) ; a-d$ : significant $(p<0.05)$ difference in term of viscous modulus $\left(G^{\prime \prime}\right)$

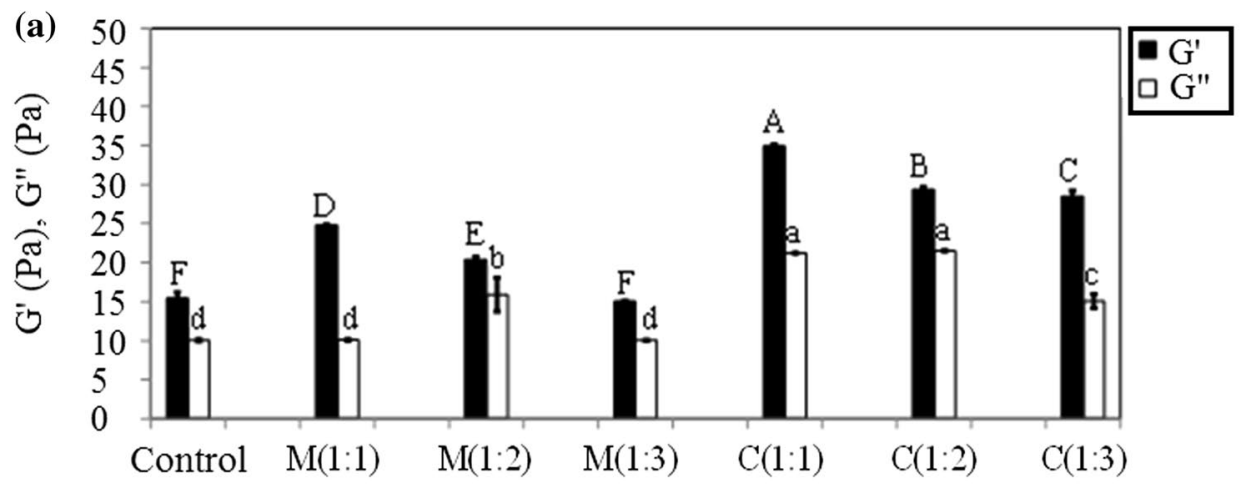

Soy protein isolate to gum karaya ratio

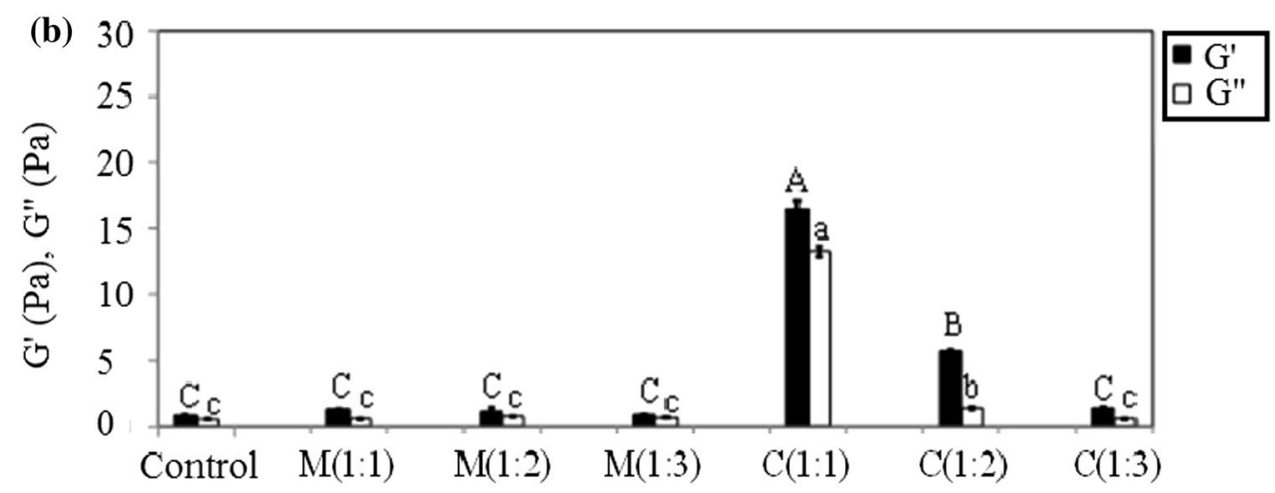

Soy protein isolate to gum karaya ratio

Fig. 6 Stability of O/W emulsions containing the native gum karaya $(G K)$; soy protein isolate $(S P I)$ and their mixtures $(M)$ and conjugated forms $(C)$ at different ratios (SPI:GK, 1:1, $1: 2$ and $1: 3) ; a-e$ significant different at $p<0.05$

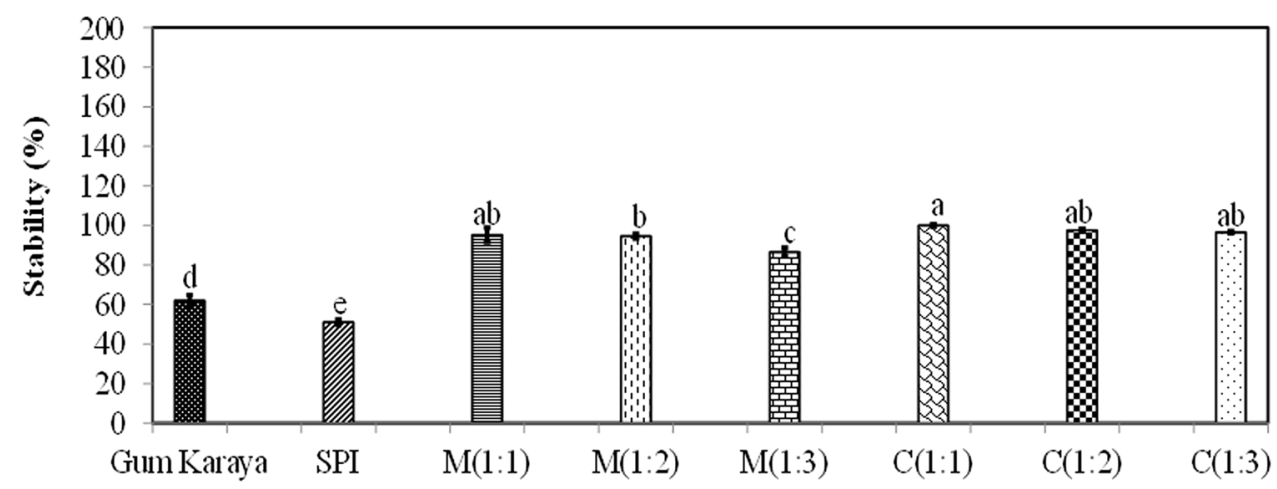

Soy protein isolate to gum karaya ratio linkage of SPI to GK may result in the new hybrid polymer with the amphiphilic structure, which could provide better resistance than the native gum against droplet collision and flocculation. It was hypothesized that the protein-gum conjugate can absorb more efficiently at the interfacial layer of $\mathrm{O} / \mathrm{W}$ emulsion due to their modified amphiphilic structure. The conjugated hybrid polymer adsorbed at $\mathrm{O} / \mathrm{W}$ interface might induce a thicker interfacial layer with stronger viscoelasticity than the native gum. Such a thicker interface can more efficiently support oil droplets and retard droplet flocculation and coalescence [21]. Previous researchers
[41, 42] also interpreted that the conjugated molecule would form a bulkier secondary layer with more efficient coverage of oil droplets than the native polymer. On the other hand, the improvement of emulsifying activity might be because of the possible electrostatic and steric interactions between oppositely charged functional groups in soy protein isolate and gum karaya.

Another concept is that the enhancement of emulsifying activity of the hybrid conjugated polymer might be also because of re-arrangement of soy protein structure and changing to the unfolding form during conjugation [42]. In 
fact, some of reactive sites (e.g. thiol groups) of the protein molecule may be trapped with other active sites, resulting in formation of disulfide bonds. Such re-arrangement of protein structure might result in stronger emulsifying activity. On the other hand, the intermolecular interactions (e.g.. van der Waals, steric, electrostatic, and hydrophobic) among protein fractions favorably contribute to the stabilization of emulsion [42, 43]. The formation of smaller droplets with more uniformity and stronger viscoelastic properties might be responsible for more desirable emulsifying activity of the conjugated polymer than the native gum (Figs. 3, 4, 5, 6). The reduction of surface tension of the oil droplets induced by the hybrid conjugated polymer might be responsible for inhibition of emulsion droplets against aggregation and further phase separation and flocculation [20].

\section{Conclusions}

The main objective of the present study was to investigate the effect of mixing and conjugation with soy protein isolate on emulsifying activity and rheological properties of gum karaya in the aqueous system and oil in water $(\mathrm{O} / \mathrm{W})$ emulsion. The current study revealed that both the mixing and conjugation process significantly affected the rheological properties and emulsifying activity of gum karaya. This might be explained by the covalent linkages induced by the dry-heating conjugation process between soy protein and gum karaya, which resulted in the formation of a new hybrid (protein-gum) polymer with an amphiphilic structure, which provided a higher molecular weight and better emulsifying activity than the native gum karaya. The conjugated hybrid polymer induced higher viscosity and stronger shear-thinning behavior than the native gum karaya in both the aqueous system and the $\mathrm{O} / \mathrm{W}$ emulsion. This might confirm the significant impact of the conjugation process on the molecular structure of gum karaya. This might also prove the nature of the covalent band in the hybrid conjugated polymer. The emulsion stabilized with the conjugated hybrid polymer had smaller droplets and better uniformity than the emulsion containing the native gum karaya. This might be explained by the fact that the conjugation of soy protein isolate to gum karaya could facilitate its adsorption to the interfacial layer of $\mathrm{O} / \mathrm{W}$ emulsion. Consequently this led to a reduction in the surface tension of the oil droplets, thus retarding phase separation and coalescence. The conjugation process exhibited the most significant $(p<0.05)$ effect on the droplet size distribution (i.e., span) of gum karaya. A further study is recommended to investigate the effect of other proteins on functional properties of gum karaya. It is also suggested that an estimation should be made of the absorption rate of karaya gum into the interfacial area before and after conjugation.
Acknowledgments We gratefully appreciate the financial support provided by the Ministry of Science, Malaysia, Technology and Innovation for supporting us through the EScience Fund (03-01-04-SF1884).

\section{References}

1. Li C, Bo Z, Haoran X, Zhiyan C, Qiao D, Xingguoet W (2013) Physicochemical properties of dry-heated peanut protein isolate conjugated with dextran or gum Arabic. J Am Oil Chem Soc 90:1801-1807

2. Yadav MP, Parris N, Johnston DB, Onwulata CI, Hicks KB (2010) Corn fiber gum and milk protein conjugates with improved emulsion stability. Carbohydr Polym 81:476-483

3. Báez GD, Busti PA, Verdini R, Delorenzi NJ (2013) Glycation of heat-treated $\beta$-lactoglobulin: effects on foaming properties. Food Res Int 54:902-909

4. Miller A, Gerrard J (2005) The Maillard reaction and food protein crosslinking. Food Biopolym Res 1:69-86

5. Cheftel JC, Cuq JL, Lorient D (1989) Modificaciones de las proteínas. In: Acribia SA (ed) Proteínas Alimentarias. Bioquímica. Propiedades Funcionales. Valor Nutritivo. Modificaciones Químicas Zaragoza España, Zaragoza, Spain, pp 304-309

6. Zhu D, Damodaran S, Lucey JA (2008) Formation of whey protein isolate (WPI)-dextran conjugates in aqueous solutions. $\mathrm{J}$ Agric Food Chem 56:7113-7118

7. Chen B, McClements DJ, Decker EA (2010) Role of continuous phase anionic polysaccharides on the oxidative stability of menhaden oil-in-water emulsions. J Agric Food Chem 58:3779-3784

8. Tolstoguzov VB (1997) Protein-polysaccharide interactions. In: Damodaran S, Parf A (eds) Food proteins and their applications. Marcel Dekker, New York, pp 171-198

9. Dickinson E, Stainsby G (1982) Colloids in food. Applied Science, London, pp 1-32

10. Silva D, Brito A, De Paula R, Feitosa J, Paula H (2003) Effect of mono and divalent salts on gelation of native, Na and deacetylated Sterculia striata and Sterculia urens polysaccharide gels. Carbohydr Polym 54:229-236

11. Singh B, Vashishtha M (2008) Development of novel hydrogels by modification of sterculia gum through radiation cross-linking polymerization for use in drug delivery. Nucl Instrum Methods B 266:2009-2020

12. Kasran M, Cui SW, Goff HD (2013) Emulsifying properties of soy whey protein isolate-fenugreek gum conjugates in oil-inwater emulsion model system. Food Hydrocol 30:691-697

13. Laemmli UK (1970) Cleavage of structural proteins during the assembly of the head of bacteriophage T4. Nature 227:680-685

14. Yadav MP, Strahan GD, Mukhopadhyay S, Hotchkiss AT, Hicks KB (2012) Formation of corn fiber gum-milk protein conjugates and their molecular characterization. Food Hydrocol 26:326-333

15. Mirhosseini H, Tabatabaee Amid B (2012) Influence of chemical extraction conditions on the physicochemical and functional properties of polysaccharide gum from durian (Durio zibethinus) seed. Molecules 17:1-16

16. Mirhosseini H, Tabatabaee Amid BT (2013) Effect of different drying techniques on flow ability characteristics and chemical properties of natural carbohydrate-protein gum from durian fruit seed. Chem Cent J 7:1-14

17. Tabatabaee Amid B, Mirhosseini H (2013) Shear flow behaviour and emulsion-stabilizing effect of natural polysaccharide-protein gum in aqueous system and oil/water $(\mathrm{O} / \mathrm{W})$ emulsion. Colloids Surf B 103:430-440

18. Neirynck N, Van Der Meeren P, Gorbe SB, Dierckx S, Dewettinck K (2004) Improved emulsion stabilizing properties of whey 
protein isolate by conjugation with pectins. Food Hydrocoll 18:949-957

19. Huang X, Kakuda Y, Cui W (2001) Hydrocolloids in emulsions: particle size distribution and interfacial activity. Food Hydrocoll 15:533-542

20. Akhtar M, Dickinson E (2007) Whey protein-maltodextrin conjugates as emulsifying agents: an alternative to gum Arabic. Food Hydrocoll 21:607-616

21. O'Regan J, Mulvihill DM (2010) Sodium caseinate-maltodextrin conjugate hydrolysates: preparation, characterisation and some functional properties. Food Chem 123:21-31

22. Thanh VH, Shibasaki K (1976) Major proteins of soybean seeds. A straightforward fractionation and their characterization. $\mathrm{J}$ Agric Food Chem 24:1117-1121

23. Davies C, Coates J, Nielsen N (1985) Inheritance and biochemical analysis of four electrophoretic variants of $\beta$-conglycinin from soybean. Theor Appl Genet 71:351-358

24. Nielsen NC (1985) The structure and complexity of the $11 \mathrm{~S}$ polypeptides in soybeans. J Am Oil Chem Soc 62:1680-1686

25. Guan JJ, Qiu AY, Liu XY, Hua YF, Ma YH (2006) Microwave improvement of soy protein isolate-saccharide graft reactions. Food Chem 97:577-585

26. Mu L, Zhao H, Zhao M, Cui C, Liu L (2011) Physicochemical properties of soy protein isolates-acacia gum conjugates. Czech J Food Sci 29:129-136

27. Utsumi S, Matsamura Y, Mori T (1997) Structure-function relationships of soy proteins. Food proteins and their applications. Marcel Dekker, New York, pp 257-292

28. Murali Mohan Babu GV, Prasad CD, Ramana Murthy KV (2002) Evaluation of modified gum karaya as carrier for the dissolution enhancement of poorly water-soluble drug nimodipine. Int J Pharm 234:1-17

29. Márquez AL, Palazolo GG, Wagner JR, Aceites G (2005) Emulsiones tipo crema preparadas a base de leche de soja. Estudios de estabilidad y determinación de las formulaciones. Grasas Aceites 56:59-66

30. Kato A, Sasaki Y, Furuta R, Kobayashi K (1990) Functional protein-polysaccharide conjugate prepared by controlled dryheating of ovalbumin-dextran mixtures. Agric Biol Chem 54:107-112

31. McClements DJ (1999) Food emulsions: principle, practice and techniques, 2nd edn. CRC Press, New York, pp 235-250
32. Williams PA (2001) Food emulsions: principles, practice, and techniques. Int J Food Sci Technol 36:223-224

33. Chevalier F, Chobert JM, Popineau Y, Nicolas MG, Haertlé T (2001) Improvement of functional properties of $\beta$-lactoglobulin glycated through Maillard reaction is related to the nature of the sugar. Int Dairy J 11:145-152

34. Kawakatsu $T$, Trägårdh $\mathrm{G}$, Trägårdh $\mathrm{C}$ (2001) Production of $\mathrm{W} / \mathrm{O} / \mathrm{W}$ emulsions and $\mathrm{S} / \mathrm{O} / \mathrm{W}$ pectin microcapsules by microchannel emulsification. Colloid Surf A 189:257-264

35. Simas-Tosin FF, Barraza RR, Petkowicz CLO, Silveira JLM, Sassaki GL, Santos EMR (2010) Rheological and structural characteristics of peach tree gum exudates. Food Hydrocoll 24:486-493

36. Everett DW, Mcleod RE (2005) Interactions of polysaccharide stabilisers with casein aggregates in stirred skim-milk yoghurt. Int Dairy J 15:1175-1183

37. Ibañez MAC, Ferrero C (2003) Extraction and characterization of the hydrocolloid from Prosopis flexuosa DC seeds. Food Res Int 36:455-460

38. McClements DJ (2007) Critical review of techniques and methodologies for characterization of emulsion stability. Crit Rev Food Sci Nutr 47:611-649

39. Akhtar M, Dickinson E (2003) Emulsifying properties of whey protein-dextran conjugates at low $\mathrm{pH}$ and different salt concentrations. Colloid Surf B 31:125-132

40. Aminlari M, Ramezani R, Jadidi F (2005) Effect of Maillardbased conjugation with dextran on the functional properties of lysozyme and casein. J Sci Food Agric 85:2617-2624

41. Mu L, Zhao M, Yang B, Zhao H, Cui C, Zhao Q (2010) Effect of ultrasonic treatment on the graft reaction between soy protein isolate and gum acacia and on the physicochemical properties of conjugates. J Agric Food Chem 58:4494-4499

42. Ettelaie R, Dickinson E, Murray BS (2005) Self-consistent-field studies of mediated steric interactions in mixed protein and polysaccharide solutions. In: Dickinson E (ed) Food colloids: interaction, microstructure and processing. Royal Society of Chemistry, Cambridge, pp 74-84

43. Dickinson E (2009) Hydrocolloids as emulsifiers and emulsion stabilizers. Food Hydrocoll 23:1473-1482 